\title{
Botulinum toxin type A prevents the phenotypic transformation of fibroblasts induced by TGF-ß1 via the PTEN/PI3K/Akt signaling pathway
}

\author{
XUE ZHANG, DONG LAN, SHUHUA NING, HONGXIA JIA and SISI YU \\ Department of Dermatology and Plastic Surgery, Beijing Chaoyang Hospital, Jingxi Campus, \\ Capital Medical University, Beijing 100043, P.R. China
}

Received August 21, 2018; Accepted May 24, 2019

DOI: $10.3892 /$ ijmm.2019.4226

\begin{abstract}
Hypertrophic scar (HS) is a common type of dermatosis. Botulinum toxin type A (BTXA) can exert an anti-HS effect; however, the regulatory mechanisms underlying this effect remain unclear. Thus, the aim of this study was to examine the effects of BTXA on phosphatase and tensin homolog deleted on chromosome ten (PTEN) expression and the fibroblast phenotypic transformation induced by transforming growth factor (TGF)- $\beta 1$, which is an important regulatory factor involved in the process of HS. For this purpose, fibroblasts were treated with various concentrations of BTXA and then treated with $10 \mathrm{ng} / \mathrm{ml}$ of TGF- $\beta 1$ with gradient concentrations of BTXA. The proliferation and apoptosis of fibroblasts were measured by cell counting kit-8 assay (CCK-8) and flow cytometry, respectively. PTEN methylation was analyzed by methylation-specific PCR (MSP) and DNA methyltransferase (DNMT) activity was determined using a corresponding kit. RT-qPCR and western blot analysis were performed to detect the transcription and translation levels. The results revealed that BTXA suppressed the proliferation and increased the apoptosis of fibroblasts treated with TGF- $\beta 1$ in a dose-dependent manner. BTXA in combination with TGF- $\beta 1$ suppressed the expression of molecules related to the extracellular matrix (ECM), epithelial-mesenchymal transition (EMT) and apoptosis. BTXA reduced the PTEN methylation level and downregulated the expression levels of methylation-associated genes. BTXA also inhibited the phosphorylation of phosphoinositide 3-kinase (PI3K) and Akt.
\end{abstract}

Correspondence to: Dr Xue Zhang, Department of Dermatology and Plastic Surgery, Beijing Chaoyang Hospital, Jingxi Campus, Capital Medical University, 5 Jingyuan Road, Shijingshan, Beijing 100043, P.R. China

E-mail: xuez_zhangx@163.com

Key words: botulinum toxin type A, transforming growth factor- $\beta 1$, hypertrophic scar, phosphatase and tensin homolog deleted on chromosome ten, phosphoinositide 3-kinase/Akt, fibroblast, methylation
On the whole, the findings of this study indicate that BTXA may inhibit fibroblast phenotypic transformation by regulating PTEN methylation and the phosphorylation of related pathways. The findings of this study can provide a theoretical basis for HS treatment.

\section{Introduction}

Skin scars could be divided into several categories, for example, hypertrophic scar (HS), keloid scar and atrophic scar (or sunken scar). Among these, HS, a benign hyperproliferative growth of dermal collagen, originates from unbalanced fibroblast cellular dynamics that result from an elevated proliferation and a reduced apoptosis of fibroblasts (1). HS is an aberrant healing response, secondary to traumatic injuries, empyrosis and surgical trauma (2). The formation of HS has been demonstrated to be relevant to a proliferative stage of wound healing, during which dermal tissue hyperplasia and the over-deposition of extracellular matrix (ECM) proteins derived from fibroblasts can cause durative fibrosis and inflammation (3).

Fibroblast-to-myofibroblast transformation is a vital event during wound healing and hypertrophic scar formation (4). Fibroblasts arise at the wound site at the ultimate inflammatory stage and the initial proliferative phase of healing wound (5). Myofibroblasts, which are differentiated from fibroblasts, are primitively produced in the local derma and hypodermal tissues around the injured skin in HS (6) in addition to other origins, for instance, bone marrow-derived fibrocytes (7), tissue-specific stem cells (8), pericytes and vascular smooth muscle cells (9) and tubular epithelial cells with epithelial-mesenchymal transition (EMT) (10). Myofibroblasts in granulation tissues can lead to HS formation; however, the roles of these myofibroblasts in the pathogenesis of HS remain unclear.

Transforming growth factor- $\beta$ (TGF- $\beta$ ) may serve as a therapeutic target for HS and may be an important regulatory factor in the process of HS (4). TGF- $\beta 1 / \mathrm{Smad} 2$ signaling can promote collagen synthesis and enhance the proliferation of human HS fibroblasts (11). A previous study revealed that TGF- $\beta$ can exert differential temporal effects on HS formation (12). Moreover, TGF- $\beta 1$ is able to induce Smad 2 nuclear translocation, finally causing the transcription of target genes, including collagens I and III (13). Moreover, the silencing of 
Smad 2 can prevent type I and III collagen overproduction in HS fibroblasts (14). Recently, multiple agents, such as baicalein (15), loureirin B (16), tetrandrine (17) and botulinum toxin type A (BTXA) (1), have been reported to exert anti-HS effects by inhibiting TGF- $\beta 1$ signaling.

Botulinum toxin is an effective neurotoxin generated from Clostridium botulinum and it has been shown to have potential for use in the treatment of wounds following trauma, burns or surgery (18). BTXA is available for clinical use in a number of countries as its safe and has effective properties in the treatment of hypertrophic scarring (20). Rasaii reported that triamcinolone in combination with BTXA was ineffective for keloid scars (21), while BTXA was demonstrated to attenuate HS growth and improve the symptoms of HS in clinical practice (22). Currently, an increasing number of studies have demonstrated that BTXA can alleviate fibrosis by regulating fibroblast behaviors in HS and capsular contracture. For instance, BTXA can attenuate HS and capsular contracture by suppressing the phenotypic transformation of fibroblasts to myofibroblasts, according to in vitro and in vivo experiments $(1,19)$. BTXA can markedly reduce the collagen deposition in HS (22-24). Furthermore, BTXA has been demonstrated to inhibit fibroblast proliferation and to reduce the level of $\alpha$-smooth muscle actin ( $\alpha$-SMA) $(25,26)$. Furthermore, BTXA can also regulate the expression levels of matrix metalloproteinase (MMP)-2 MMP-9, and collagen types I and III, in addition to inhibiting capsule formation (27).

HS fibroblasts have been reported to possess malignant characteristics, including hyperproliferation, anti-apoptosis and atypical differentiation (28-31). Tansdifferentiation, proliferation and apoptosis have been demonstrated to be regulated by the phosphatidylinositol 3-kinase (PI3K)/Akt signaling pathway in HS fibroblasts (32-34). Moreover, Akt is also involved in cell motility and ECM deposition $(35,36)$. Phosphatase and tensin homologue deleted on chromosome ten (PTEN) protein has reported as a tumor suppressor and it can negatively regulate Akt signaling to inhibit the proliferation of HS fibroblasts (37). Inactive PTEN expression has been observed in several fibrotic diseases (38-40). Therefore, HS may be relevant to the antagonistic association between PTEN and Akt. In the present study, our aim was to explore the potential mechanisms involved in PTEN/PI3K/Akt signaling and the effects of BTXA on the phenotypic transformation of fibroblasts induced by TGF- $\beta 1$. Our findings are expected to provide a theoretical basis for the treatment of HS.

\section{Materials and methods}

Fibroblast culture and morphological identification. Murine L929 fibroblasts (41) (Cat no. CC-Y2049, ATCC) were maintained in the Dulbecco's minimal Eagle's medium with $10 \%$ fetal bovine serum, penicillin $(100 \mathrm{U} / \mathrm{ml})$ and streptomycin $(100 \mathrm{mg} / \mathrm{ml})$ at $37^{\circ} \mathrm{C}$ with $5 \% \mathrm{CO}_{2}$ (all purchased from Invitrogen; Thermo Fisher Scientific). The morphological changes of the fibroblasts were observed using an inverted microscope (Nikon). For vimentin identification, the fibroblasts were fixed with $4 \%$ paraformaldehyde for $0.5 \mathrm{~h}$ and incubated in $0.5 \%$ Triton X-100 (Sigma-Aldrich) for $20 \mathrm{~min}$. After being blocked in bovine serum albumin (BSA; Solarbio), the fibroblasts were incubated with anti-vimentin antibody (M00235-1,
1:100; BosterBio) for $1 \mathrm{~h}$ at room temperature. The fibroblasts were then incubated with goat anti-rabbit IgG H\&L secondary antibodies (1:5,000; ab6721; Abcam) for $1 \mathrm{~h}$. The nuclei were stained with Hoechst 33258 (Beyotime) for $20 \mathrm{~min}$ at $37^{\circ} \mathrm{C}$ in the dark and the stained fibroblasts were observed under a fluorescence microscope (Nikon).

Fibroblast treatment and viability assay. Fibroblasts $\left(2 \times 10^{5}\right)$ were maintained in 96-well plates for $24 \mathrm{~h}$, and fresh media were then added with various concentrations of BTXA $(0,0.125,0.25,0.5,1$ and $2 \mathrm{UI} / \mathrm{ml}$; Lanzhou Biochemical Co.). Cell counting kit-8 (CCK-8; Beyotime) solution $(20 \mu \mathrm{l})$, with the original concentration in the kit, was incubated with the fibroblasts for an additional $2 \mathrm{~h}$ at $37^{\circ} \mathrm{C}$ when the fibroblasts were incubated for 12, 24 and $48 \mathrm{~h}$, respectively. Thereafter, other fresh fibroblasts were incubated with TGF- $\beta 1(10 \mathrm{ng} / \mathrm{ml})$ (4) for $3 \mathrm{~h}$, and the fibroblasts were subsequently treated with low, medium and high concentrations of BTXA $(0.25,0.5$ and $1 \mathrm{UI} / \mathrm{ml}$, respectively). Subsequently, $20 \mu \mathrm{l} \mathrm{CCK}-8$ were incubated with the fibroblasts for an additional $2 \mathrm{~h}$ at $37^{\circ} \mathrm{C}$, for the determination of fibroblast viability. The absorbance of $450 \mathrm{~nm}$ was determined using a multimode detector (BioTek Instruments).

Apoptosis analysis. Apoptosis was detected according to the protocol of the Annexin V-fluorescein isothiocyanate (FITC)/propidium iodide (PI) apoptosis detection kit (KeyGEN). The results were analyzed using a FACSCalibur flow cytometer (BD Biosciences). The cells were then identified using Annexin V-FITC/PI double fluorescence staining as follows: Unlabeled, viable cells; PI-stained cells, necrotic cells; Annexin V-FITC-bounded cells, early apoptotic cells; and double-labeled cells, late apoptotic cells.

Immunofluorescence assay. Fibroblasts were fixed with $4 \%$ paraformaldehyde for $20 \mathrm{~min}$ and washed with PBS. After being blocked in bovine serum albumin (BSA), the fibroblasts were incubated first with anti- $\alpha$-SMA antibody (A03744, 1:200; BosterBio) overnight at $4^{\circ} \mathrm{C}$ and then with Cy3-conjugated goat anti-rabbit secondary antibodies (BA1032, 1:500; Beyotime) for $0.5 \mathrm{~h}$. Subsequently, the fibroblasts were stained with 4',6-diamidino-2-phenylindole (DAPI; Beyotime) and images were captured under a fluorescence microscopy (Nikon).

Methylation-specific PCR (MSP). DNA was isolated using the DNeasy tissue kit (Qiagen) and then analyzed by MSP using bisulfite-modified DNA. A total of $1 \mu \mathrm{g}$ purified DNA was treated according to the CpGenome DNA Modification kit (Intergen). CpGenome Universal Methylated DNA (Intergen) and normal mouse fibroblast DNA served as methylated and unmethylated controls, respectively. The amplification for methylated (M) PTEN (forward, 5'-TTGATTAACGCGGTT AGTTAGTTC-3' and reverse, 5'-AACGCATATCCTACC GCAATAC-3') and unmethylated (U) PTEN (forward, 5'-GTG TTGATTAATGTGGTTAGTTAGTTT-3' and reverse, 5'-CCA AACACATATCCTACCACAATAC-3') was performed under the following conditions: At $94^{\circ} \mathrm{C}$ for $2 \mathrm{~min}$, then 36 cycles at $94^{\circ} \mathrm{C}$ for $30 \mathrm{sec}$, at $54^{\circ} \mathrm{C}$ for $30 \mathrm{sec}$ and at $72^{\circ} \mathrm{C}$ for $45 \mathrm{sec}$, and finally $7 \mathrm{~min}$ at $72^{\circ} \mathrm{C}$. PCR products were analyzed on a $2 \%$ agarose gel with ethidium bromide. 
Table I. Sequences of primers used for RT-qPCR assays.

\begin{tabular}{lll}
\hline Gene name & \multicolumn{1}{c}{ Forward (5'-3') } & \multicolumn{1}{c}{ Reverse $\left(5^{\prime}-3^{\prime}\right)$} \\
\hline Collagen I & ACTGTCTTGCCCCAAGTTCC & TGGGCATCTGGTTTAGCCTT \\
Collagen III & ACGTAGATGAATTGGGATGCAG & GGGTTGGGGCAGTCTAGTG \\
$\alpha$-SMA & AGGGGAATGAAAAGCCGGAA & TAGGATATGCCTGGGGGTC \\
MMP-2 & ACCATCGAGACCATGCGG & CTCCCCCAACACCAGTGC \\
MMP-9 & TTCTGCCCTACCCGAGTGGA & CATAGTGGGAGGTGCTGTCGG \\
PTEN & AATTCCCAGTCAGAGGCGCTATGT & GATTGCAAGTTCCGCCACTGAACA \\
DNMT1 & AGTGCAAGGCGTGCAAAGATATGG & TGGGTGATGGCATCTCTGACACAT \\
DNMT3a & GCCGAATTGTGTCTTGGTGGATGACA & CCTGGTGGAATGCACTGCAGAAGGA \\
DNMT3b & TTCAGTGACCAGTCCTCAGACACGAA & TCAGAAGGCTGGAGACCTCCCTCTT \\
GAPDH & GTAGAGGCAGGGATGATGTTCT & CTTTGGTATCGTGGAAGGACTC
\end{tabular}

$\alpha$-SMA, $\alpha$ smooth muscle actin; MMP, matrix metalloproteinase; PTEN, phosphatase and tensin homolog deleted on chromosome ten; DNMT, DNA methyltransferase.

DNA methyltransferase (DNMT) activity. The nuclear protein was extracted from the fibroblasts using the Nuclear Extract kit (Active Motif). Total DNMT activity was measured according to the protocol of the EpiQuik DNMT Activity/Inhibition Assay Ultra kit (Epigentek).

RNA extraction, cDNA synthesis and reverse transcriptionquantitative PCR (RT-qPCR). Total RNA was extracted from the mouse fibroblasts using TRIzol reagent (Invitrogen; Thermo Fisher Scientific). In brief, TRIzol reagent and chloroform were added to the samples and mixed for $5 \mathrm{~min}$, and the supernatant was recovered by centrifugation, at $10,000 \mathrm{x} \mathrm{g}$, at $4^{\circ} \mathrm{C}$ for $20 \mathrm{~min}$. The supernatant was then incubated with an equal volume of isopropyl alcohol and then centrifuged for $10 \mathrm{~min}$. After dislodging the supernatants, $75 \%$ ethanol was added to wash the precipitate and the RNA was eluted with nuclease-free water. The purity and content of the reverse transcription was determined using a NanoDrop 2000 spectrophotometer (Thermo Fisher Scientific). cDNA was obtained by RNA with mixture in the PrimeScript ${ }^{\mathrm{TM}} 1$ st Strand cDNA Synthesis kit (Takara). The reactions (primers are listed in Table I) were conducted with a LightCycler system (Roche Applied Science) using the following parameters: at $95^{\circ} \mathrm{C}$ for $10 \mathrm{~min}, 40$ cycles at $95^{\circ} \mathrm{C}$ for $15 \mathrm{sec}$ and at $60^{\circ} \mathrm{C}$ for $60 \mathrm{sec}$. GAPDH was used as the internal control and the results were calculated using the $2^{-\Delta \Delta \mathrm{Cq}}$ method (42).

Western blot analysis. The fibroblasts were lysed in lysis buffer (Beyotime) and centrifuged for supernatant recovery. The protein concentrations were determined using a BCA kit (Beyotime). After being separated by $10 \%$ SDS-PAGE, the proteins $(20 \mu \mathrm{g})$ were transferred onto nitrocellulose membranes (Millipore) and blocked with 5\% non-fat dry milk for $1 \mathrm{~h}$ at room temperature. The membranes were then first incubated at $4^{\circ} \mathrm{C}$ overnight with anti-PTEN (1:200; cat. no. 9188), anti-DNMT1 (1:1,000; cat. no. 5032), anti-DNMT3a (1:1,000; cat. no. 49768), anti-DNMT3b (1:1,000; cat. no. 48488$)$, anti-PI3K $(1: 1,000$; cat. no. 4255$)$, anti-p-PI3K (1:1,000; cat. no. 4228), anti-Akt (1:1,000; cat. no. 4685), anti-p-Akt (1:1,000; cat. no. 4056), anti-MMP-2 (1:1,000; cat. no. 87809) (all from Cell Signaling Technology), anti- $\alpha-S M A$ (1:350; cat. no. A03744, BosterBio), anti-MMP-9 (1:500; sc-21733), anti-caspase-3 (1:200; sc-271759), anti-collagen I (1:1,000; sc-376350), anti-collagen III (1:1,000; sc-271249) and anti- $\beta$-actin (1:1,000; sc-58673) (all from Santa Cruz Technology) antibodies and then with secondary antibodies [goat anti-rabbit IgG H\&L (HRP) (1:5,000; ab6721, Abcam)] for $2 \mathrm{~h}$ at room temperature. The proteins were visualized using an ECL kit (Amersham Biosciences, Germany), and analyzed with the Bio-Rad ChemiDoc ${ }^{\mathrm{TM}}$ XRS+ System and Image $\mathrm{Lab}^{\mathrm{TM}}$ Software version 4.1 (Bio-Rad Laboratories, Inc., Hercules, CA, USA).

Statistical analysis. All results are presented as the means \pm standard deviation. All statistical analyses were performed with SPSS 17.0 software (SPSS, Inc.), and the differences between two groups were analyzed by a t-test or by one-way ANOVA with Dunnett's post hoc test for multiple group comparisons. $\mathrm{P}<0.05$ was considered to indicate a statistically significant difference.

\section{Results}

Effect of BTXA on the viability of mouse L929 fibroblasts. The fibroblasts exhibited spindle-like, ellipse and irregular shapes with large nuclei and transparent cytoplasms (Fig. 1A). Moreover, vimentin expression was significantly positive in the fibroblasts (Fig. 1B). However, BTXA was found to inhibit the viability of the fibroblasts in a dose- and time-dependent manner (Fig. 1C).

TGF- $\beta 1$ is a crucial factor for the induction of the transformation of fibroblasts into myofibroblasts. In this study, the proliferation of fibroblasts treated with TGF- $\beta 1$ was markedly increased. However, the increased viability of the fibroblasts induced by TGF- $\beta 1$ was significantly inhibited by BTXA in a concentration-dependent manner $(\mathrm{P}<0.05$; Fig. 2A). Moreover, the apoptosis of the fibroblasts was markedly increased by BTXA (P<0.01; Fig. 2B).

BTXA prevents over-deposition of ECM components in fibroblasts. The mRNA expression levels of collagen I, 

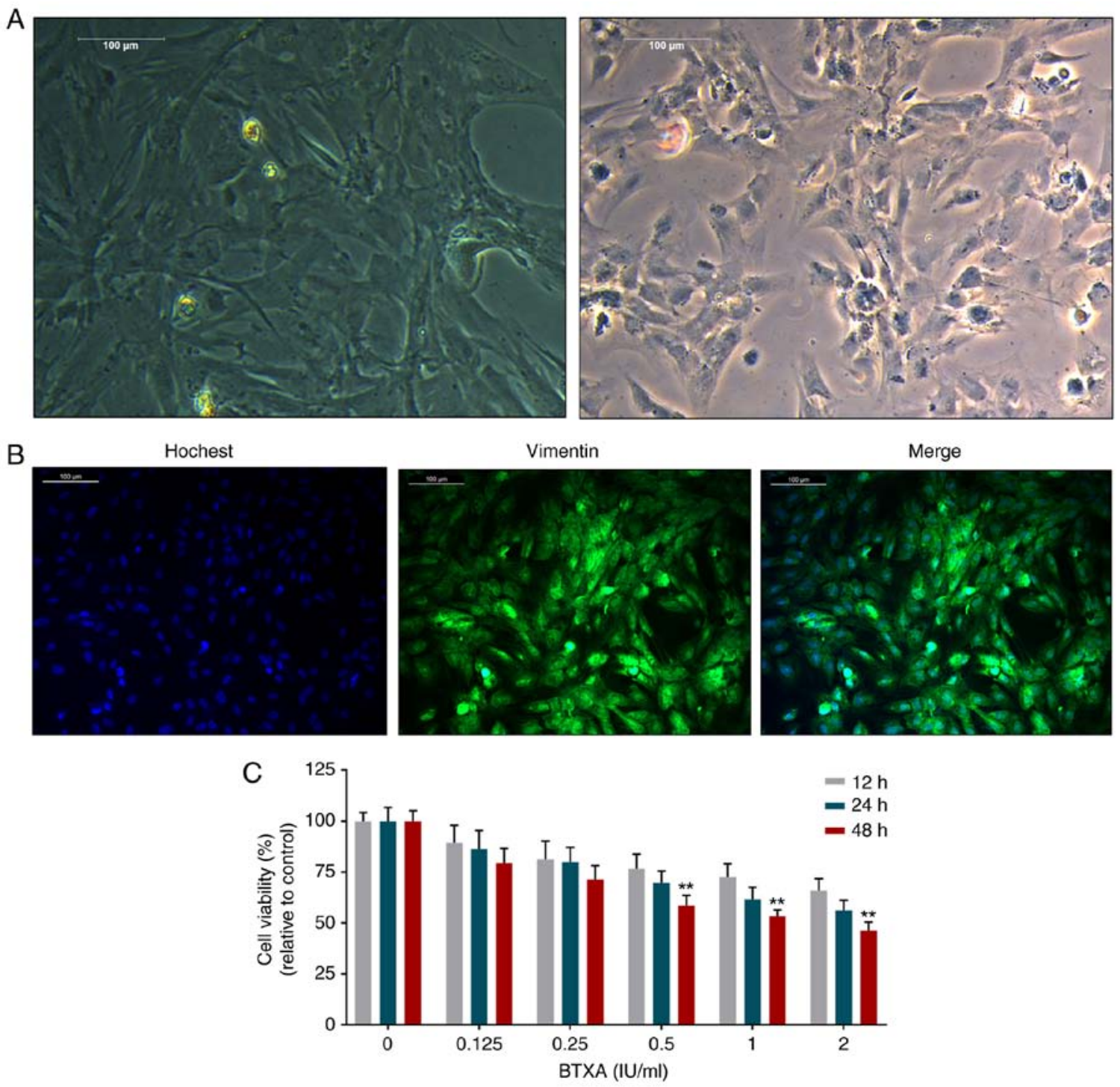

Figure 1. Effect of BTXA on the viability of mouse L929 fibroblasts. (A) The morphological changes of fibroblasts observed under a microscope. (B) The vimentin identification of fibroblasts with Hoechst 33258 was determined by immunofluorescence assay. (C) BTXA inhibited fibroblast viability, which was detected by cell counting kit- 8 assay in a dose- $(0,0.125,0.25,0.5,1$ and $2 \mathrm{IU} / \mathrm{ml})$ and time- $(12,24$ and $48 \mathrm{~h})$ dependent manner. ${ }^{* *} \mathrm{P}<0.01 \mathrm{vs}$. control. BTXA, botulinum toxin type A.

collagen III and $\alpha$-SMA were notably enhanced by TGF- $\beta 1$; however, the increased mRNA levels of these molecules were evidently reduced by treatment with gradient concentrations of BTXA (P<0.01; Fig. 3A). Similarly, BTXA suppressed the high protein levels of collagen I, collagen III and $\alpha$-SMA induced by TGF- $\beta 1$ (P<0.01; Fig. 3B). Furthermore, $\alpha$-SMA was found to be acutely expressed in fibroblasts by treatment with TGF- $\beta 1$; however, $\alpha$-SMA expression was markedly inhibited by treatment with medium and high concentrations of BTXA (Fig. 3C).

BTXA suppresses the expression of MMP-2 and MMP-9. To explore the potential role of BTXA in EMT, we detected the levels of MMP-2 and MMP-9. TGF- $\beta 1$ significantly enhanced the mRNA expression levels of MMP-2 and MMP-9. However, BTXA inhibited these expression levels in a dose-dependent manner $(\mathrm{P}<0.01$; Fig. $4 \mathrm{~A})$. Moreover, the elevated protein levels of MMP-2 and MMP-9 induced by TGF- $\beta 1$ were also notably suppressed by BTXA (P<0.01; Fig. 4B).
BTXA enhances PTEN expression and inhibits apoptosis. The expression of PTEN was significantly reduced by TGF- $\beta 1$, while BTXA markedly increased PTEN expression at the transcriptional and translational level $(\mathrm{P}<0.01$; Fig. 5A and B). Additionally, the protein level of cleaved caspase- 3 was notably inhibited by TGF- $\beta 1$, whereas, BTXA markedly increased cleaved caspase- 3 expression. The expression of cleaved caspase- 3 in the fibroblasts treated with a high concentration of BTXA $(1 \mathrm{UI} / \mathrm{ml})$ did not differ significantly from that in the untreated fibroblasts. Nevertheless, the expression of pro-caspase- 3 exhibited an opposite trend ( $\mathrm{P}<0.01$; Fig. 5B).

BTXA blocks PTEN methylation. To further elucidate the mechanisms of action of BTXA in fibroblasts, we measured the methylation level of PTEN. PTEN methylation was induced by TGF- $\beta 1$, but prevented by BTXA (Fig. 5 C). Moreover, we detected DNMT activity and determined the expression levels of several genes related to DNA methylation. DNMT activity was intensified by TGF- $\beta 1$, and 

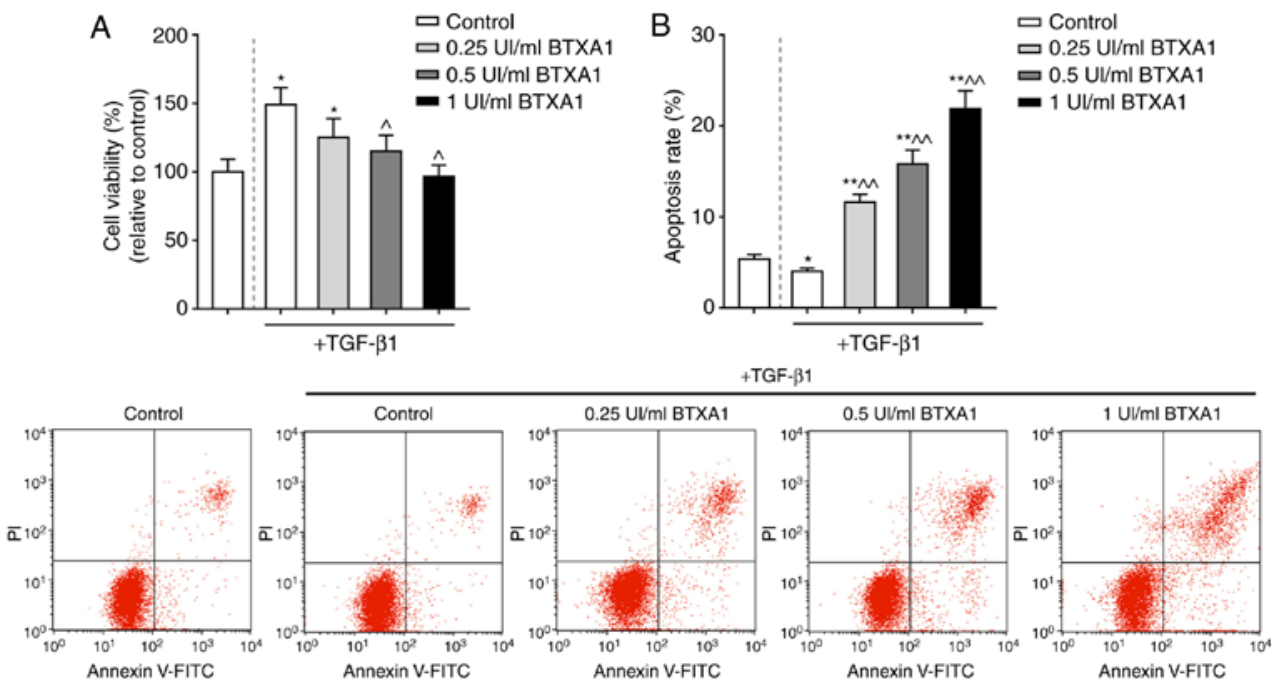

Figure 2. BTXA suppresses fibroblast viability and promotes apoptosis. (A) BTXA suppressed the high fibroblast viability induced by TGF- $\beta 1$. (B) BTXA increased the apoptosis of fibroblasts induced by $10 \mathrm{ng} / \mathrm{ml}$ of TGF- $\beta 1$. Dotted line separation represents whether or not fibroblasts were treated with TGF- $\beta 1$. Data are shown as the means $\pm \mathrm{SD}, \mathrm{n}=3 .{ }^{*} \mathrm{P}<0.05$ and ${ }^{* *} \mathrm{P}<0.01$ vs. control without TGF- $\beta 1 ;{ }^{\wedge} \mathrm{P}<0.05$ and ${ }^{\wedge \wedge} \mathrm{P}<0.01$ vs. control with TGF- $\beta 1$. BTXA, botulinum toxin type A; TGF- $\beta 1$, transforming growth factor- $\beta 1$.
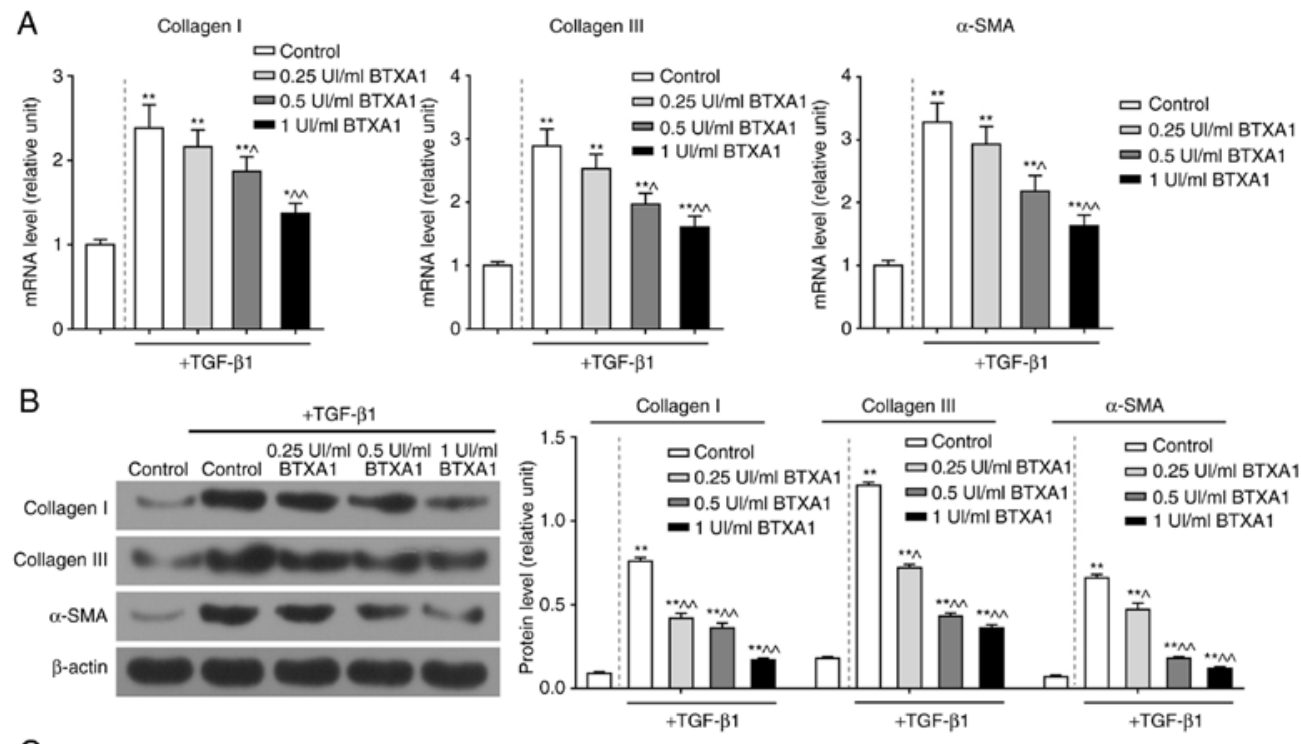

C
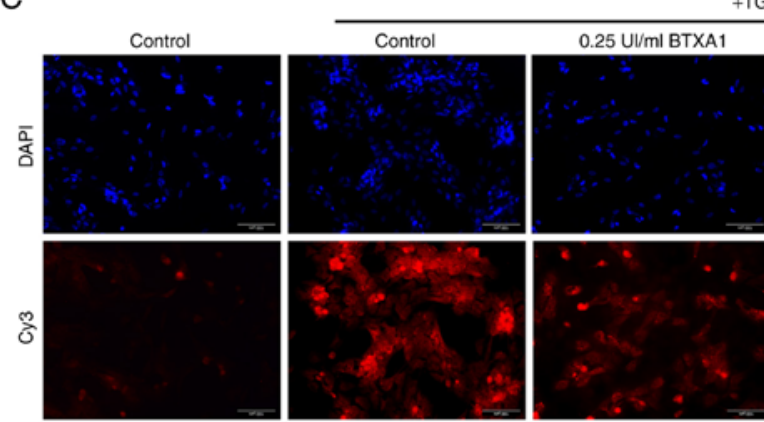

TGF- $\beta 1$
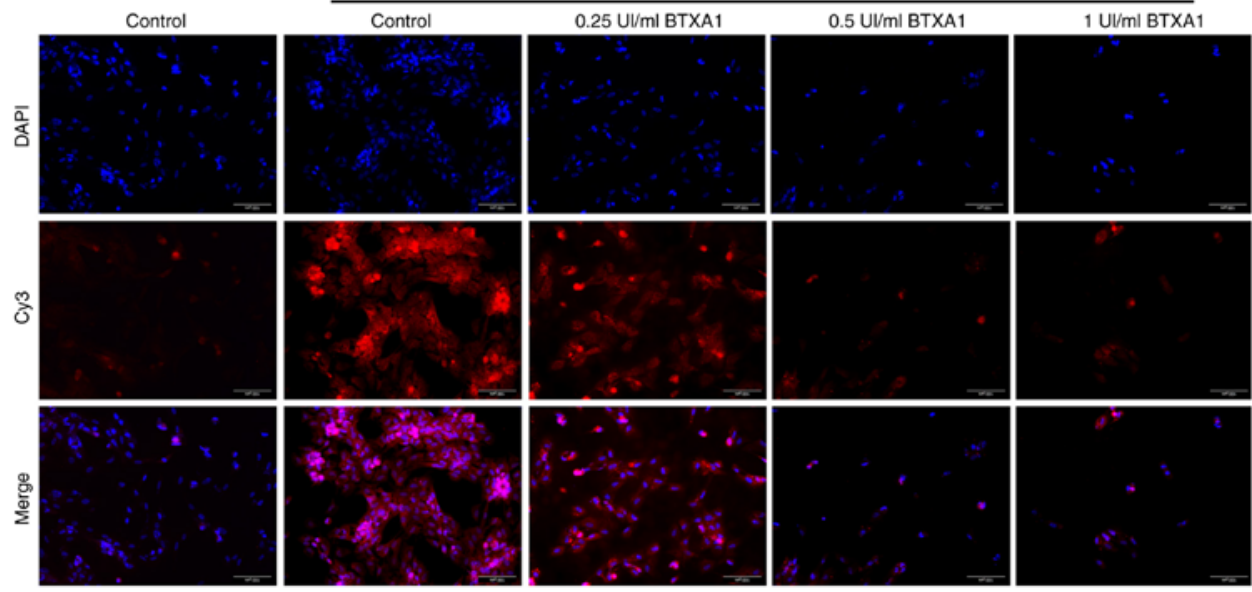

Figure 3. BTXA prevents extracellular matrix (ECM) over-deposition in fibroblasts. BTXA decreased the high expression levels of collagen I, collagen III and $\alpha$-SMA induced by $10 \mathrm{ng} / \mathrm{ml}$ of TGF- $\beta 1$ in fibroblasts. The mRNA and protein levels of collagen I, collagen III and $\alpha$-SMA were detected by (A) RT-qPCR and (B) western blot analysis, respectively. (C) $\alpha$-SMA expression was determined by immunofluorescence. $\beta$-actin was used as an internal control. Dotted line separation represents whether or not fibroblast were treated with TGF- $\beta 1$. Data were shown as the means $\pm \mathrm{SD}, \mathrm{n}=3$. ${ }^{*} \mathrm{P}<0.05$ and ${ }^{* *} \mathrm{P}<0.01$ vs. control without TGF- $\beta 1 ;{ }^{\wedge} \mathrm{P}<0.05$ and ${ }^{\wedge} \mathrm{P}<0.01$ vs. control with TGF- $\beta 1$. BTXA, botulinum toxin type A; TGF- $\beta 1$, transforming growth factor- $\beta 1$. 
A

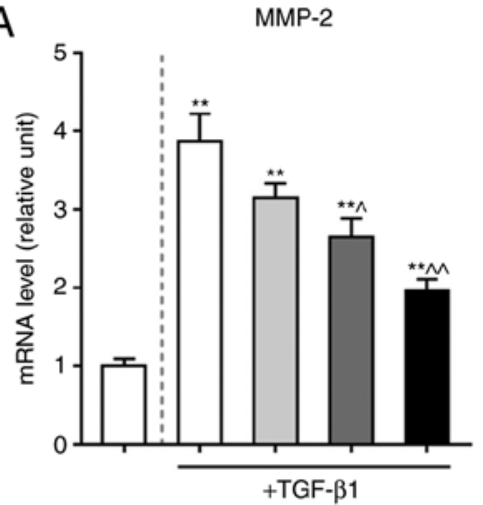

MMP-9

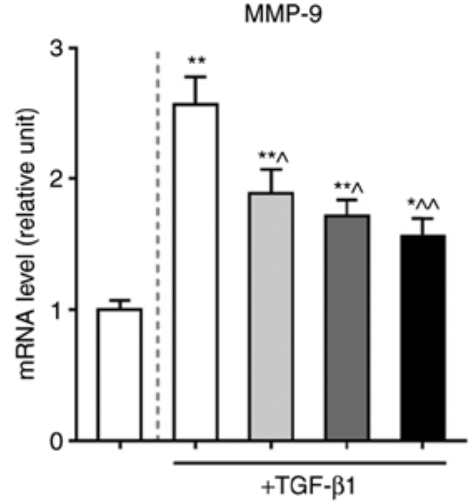

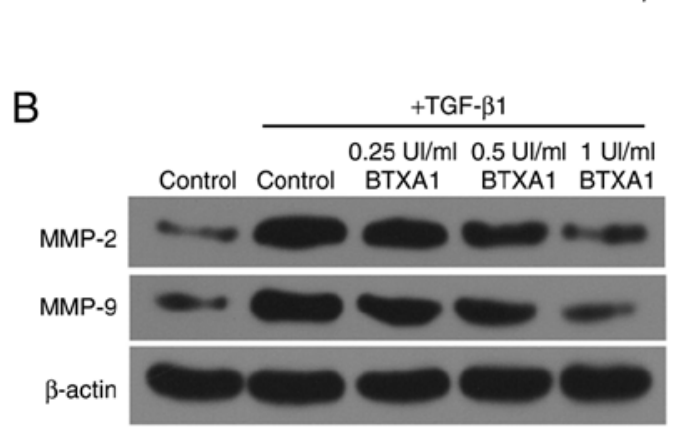

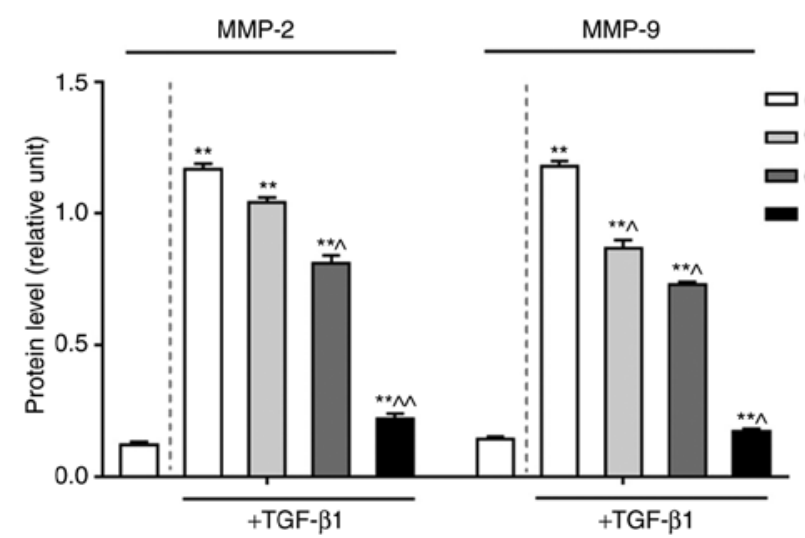

Figure 4. BTXA suppresses the expression levels of MMP-2 and MMP-9. BTXA decreased the high expression levels of MMP-2 and MMP-9 induced by $10 \mathrm{ng} / \mathrm{ml}$ of TGF- $\beta 1$ in fibroblasts. The mRNA and protein levels of MMP-2 and MMP-9 were respectively detected by (A) RT-qPCR and (B) western blot analysis, respectively. $\beta$-actin was used as an internal control. Dotted line separation represents whether or not fibroblast were treated with TGF- $\beta 1$. Data are shown as the means $\pm \mathrm{SD}, \mathrm{n}=3$. ${ }^{*} \mathrm{P}<0.05$ and ${ }^{* *} \mathrm{P}<0.01$ vs. control without TGF- $\beta 1 ;{ }^{\wedge} \mathrm{P}<0.05$ and ${ }^{\wedge} \mathrm{P}<0.01$ vs. control with TGF- $\beta 1$. BTXA, botulinum toxin type A; TGF- $\beta 1$, transforming growth factor- $\beta 1$; MMP, matrix metalloproteinase.

was attenuated by BTXA ( $<<0.05$; Fig. 6A). Moreover, the enhanced mRNA and protein levels of DNMT1, DNMT3a and DNMT3b induced by TGF- $\beta 1$ were evidently decreased by BTXA $(\mathrm{P}<0.05$; Fig. $6 \mathrm{~B}$ and $\mathrm{C})$.

BTXA inactivates the phosphorylation of PI3K and Akt. The expression levels of total PI3K and Akt remained unaltered in the fibroblasts (Fig. 7A). However, the levels of phosphorylated (p)-PI3K/PI3K and p-Akt/Akt were markedly increased by TGF- $\beta 1$ (Fig. 7B and C). Moreover, BTXA notably suppressed the ratio of $\mathrm{p}-\mathrm{PI} 3 \mathrm{~K} / \mathrm{PI} 3 \mathrm{~K}$ and $\mathrm{p}-\mathrm{Akt} / \mathrm{Akt}(\mathrm{P}<0.01)$.

\section{Discussion}

BTXA has been widely applied in clinical therapies including hyperhidrosis, spasticity, facial muscular hypertrophy and muscular contraction in humans (43). Recently, studies have demonstrated that BTXA is involved in the pathogenesis of dermal fibrosis. BTXA can effectively prevent the differentiation of fibroblasts into myofibroblasts by inhibiting $\alpha$-SMA expression (19). Moreover, BTXA is able to notably suppress the proliferation of fibroblasts in scar tissue by inhibiting $\alpha$-SMA and myosin II expression (25). BTXA has also been demonstrated to attenuate HS by preventing collagen deposition $(23,26)$. In this study, BTXA inhibited the expression levels of ECM-related molecules and suppressed PTEN methylation. We also found that PI3K/Akt was involved in the regulatory mechanisms of BTXA in mouse fibroblasts.
The formation and remodeling of HS has been revealed to be relevant to aberrant fibroblast proliferation and differentiation (44). In this study, we found that BTXA inhibited fibroblast viability in a dose-dependent manner. Furthermore, TGF- $\beta$ has been shown to be associated with HS. For instance, a TGF- $\beta 1$ inhibitor has been demonstrated to alleviate scars and improve HS morphological characteristics in xenograft mice with human HS (45). The antagonist peptide of TGF- $\beta$ has been reported to improve the fibrotic behaviors of human fibroblasts derived from HS (46). In this study, TGF- $\beta 1$ enhanced fibroblast viability and inhibited apoptosis. However, BTXA partially reversed the effects of TGF- $\beta 1$ on fibroblasts.

The accumulated fibroblasts and myofibroblast caused by proliferation, activation and differentiation can induce massive collagen deposition, resulting in ECM deposition below the derma. These activated fibroblasts can be identified by an increased expression of $\alpha$-SMA (43). $\alpha$-SMA expression is relevant to the phenotypic transformation of fibroblasts into myofibroblasts during the wound healing process (44). The decreased ratio of collagen I/collagen III has been found in human HS (47). Furthermore, collagen I expression in human HS-derived fibroblasts has been shown to be significantly suppressed by the knockdown of TGF- $\beta$ receptor I and wound scars were also shown to be decreased in rabbits (48). In this study, the elevated expression levels of collagen I, collagen III and $\alpha$-SMA induced by TGF- $\beta 1$ were suppressed by BTXA. Additionally, fibroblasts have been reported to degrade fibrin clots by generating MMPs and their inhibitors (TIMPs), 
A

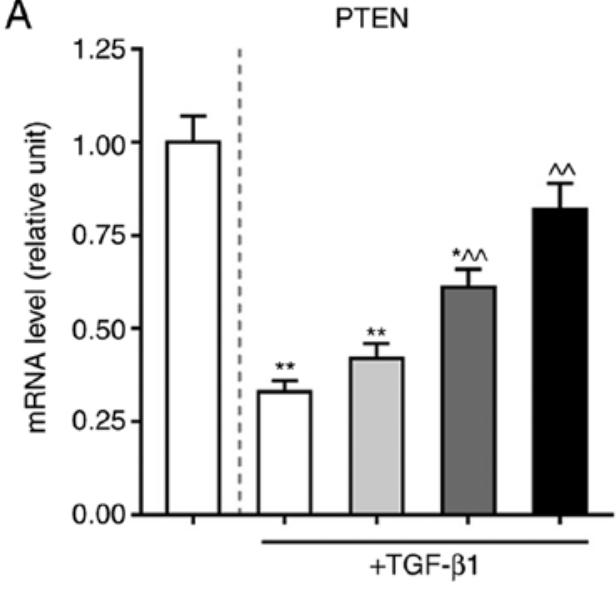

B

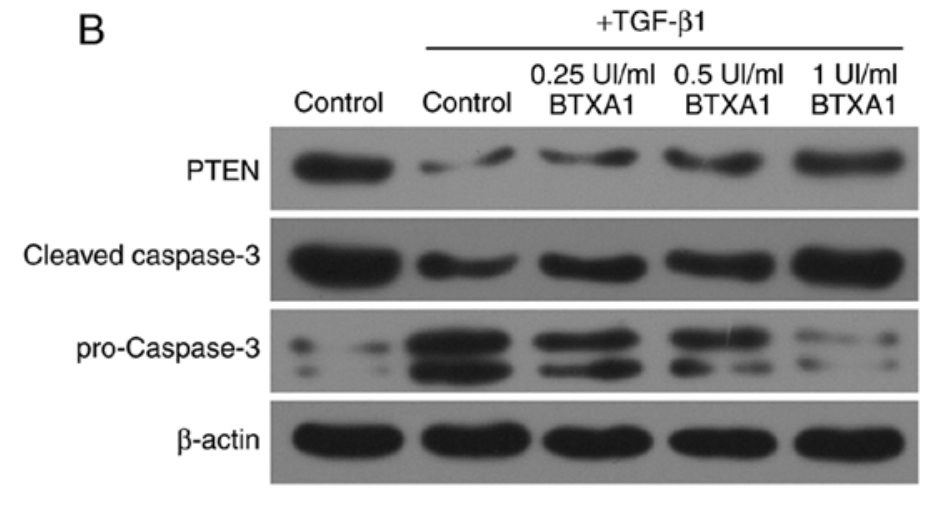

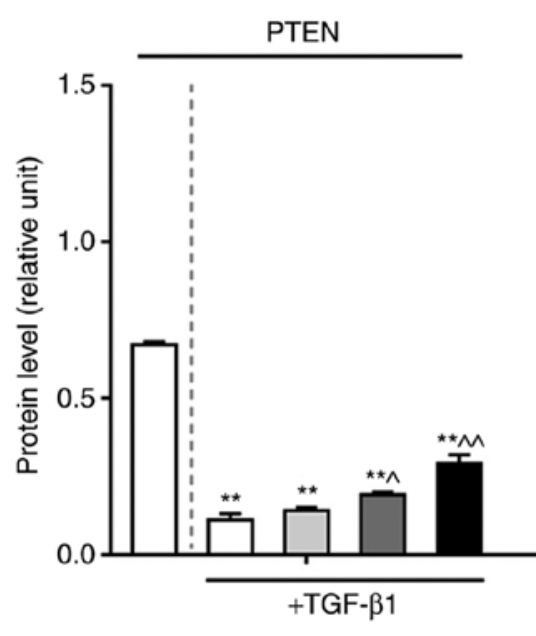

Cleaved caspase-3

pro-Caspase-3

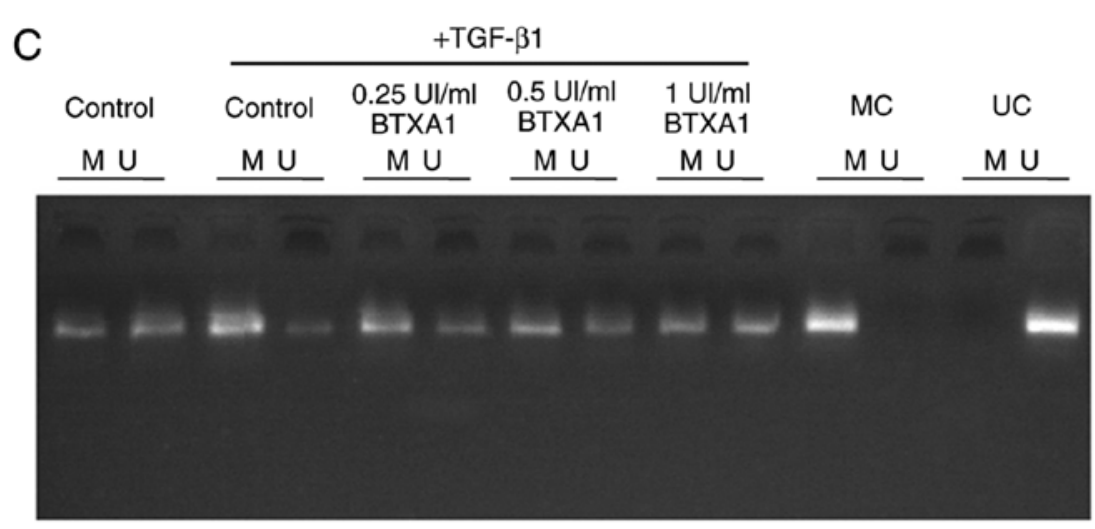

Figure 5. Effect of BTXA on PTEN and caspase-3 expression, as well as PTEN methylation. (A) Effect of treatment of fibroblasts, which were cultured with or without $10 \mathrm{ng} / \mathrm{ml}$ of TGF- $\beta 1$, with various concentrations $(0.25,0.5$ and $1 \mathrm{UI} / \mathrm{ml})$ of BTXA on the mRNA expression of PTEN, as determined by RT-qPCR. (B) Effects of BTXA on the protein levels of PTEN, pro-caspase-3 and cleaved-caspase-3, as detected by western blot analysis. (C) PTEN methylation was measured by methylation-specific PCR (MSP). M, methylated; U, unmethylated; MC, methylated control; UC, unmethylated control. $\beta$-actin was used as an internal control. Dotted line separation represents whether or not fibroblast were treated with TGF- $\beta 1$. Data are shown as the means $\pm \mathrm{SD}, \mathrm{n}=3$. ${ }^{*} \mathrm{P}<0.05$ and ${ }^{* *} \mathrm{P}<0.01$ vs. control without TGF- $\beta 1 ;{ }^{\wedge} \mathrm{P}<0.05$ and ${ }^{\wedge} \mathrm{P}<0.01$ vs. control with TGF- $\beta 1$. BTXA, botulinum toxin type A; TGF- $\beta 1$, transforming growth factor- $\beta 1$; PTEN, phosphatase and tensin homolog deleted on chromosome ten.

leading to a disorder of matrix formation and degradation (49). The enhanced expression levels of MMP-2 and MMP-9 have been shown to be associated with decreased levels of collagen I and collagen III in HS tissues (50). In this study, we found that TGF- $\beta 1$ significantly increased the MMP-2 and MMP-9 expression at the transcriptional and translational levels. However, BTXA treatment markedly altered these trends.

PTEN has been reported to inhibit the proliferation and functions of HS fibroblasts (37). A recent study revealed that
PTEN overexpression was involved in the inhibition of glial scar formation (51). In this study, we also found that PTEN expression was inhibited by TGF- $\beta 1$ and was upregulated by BTXA in fibroblasts, indicating that BTXA may suppress HS formation in vitro. Moreover, PTEN is also a key regulator of apoptosis (52). The apoptosis is detected based on the activation of caspase-3, which occurs in apoptotic death (53). In this study, we found that the pro-caspase- 3 expression was elevated, while the cleaved-caspase- 3 level was decreased by 


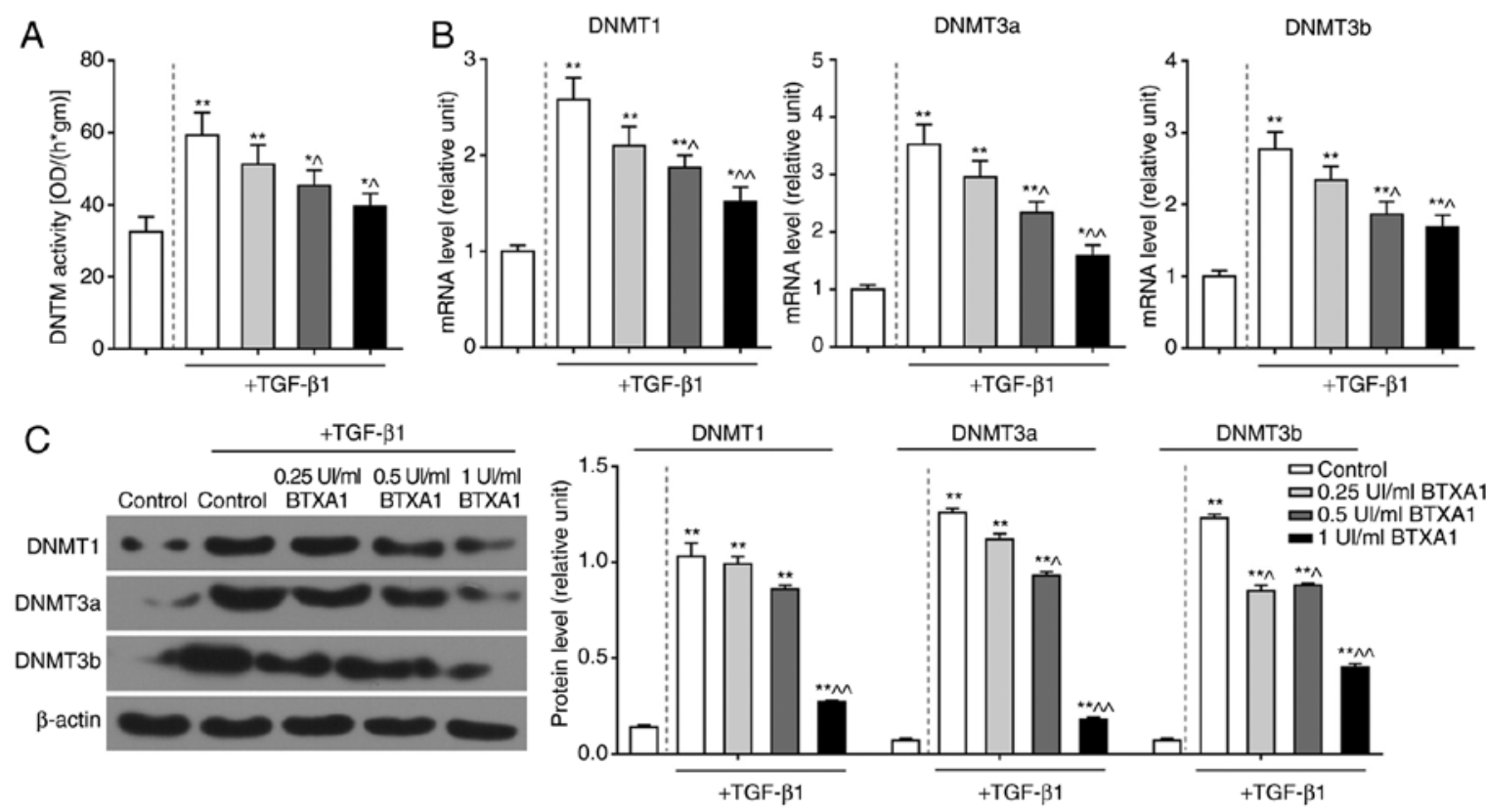

Figure 6. BTXA inhibits the activities of DNMTs. (A) The high DNMT activity induced by $10 \mathrm{ng} / \mathrm{ml}$ of TGF- $\beta 1$ was decreased by BTXA. (B and C) The mRNA and protein levels of DNMT1, DNMT3a and DNMT3b were determined by RT-qPCR and western blot analysis, respectively. $\beta$-actin was used as an internal control. Dotted line separation represents whether or not fibroblasts were treated with TGF- $\beta 1$. Data are shown as the means $\pm \mathrm{SD}, \mathrm{n}=3$. ${ }^{*} \mathrm{P}<0.05$ and ${ }^{* *} \mathrm{P}<0.01$ vs. control without TGF- $\beta 1 ;{ }^{\wedge} \mathrm{P}<0.05$ and ${ }^{\wedge \wedge} \mathrm{P}<0.01$ vs. control with TGF- $\beta 1$. BTXA, botulinum toxin type A; TGF- $\beta 1$, transforming growth factor- $\beta 1$; DNMT, DNA methyltransferase.

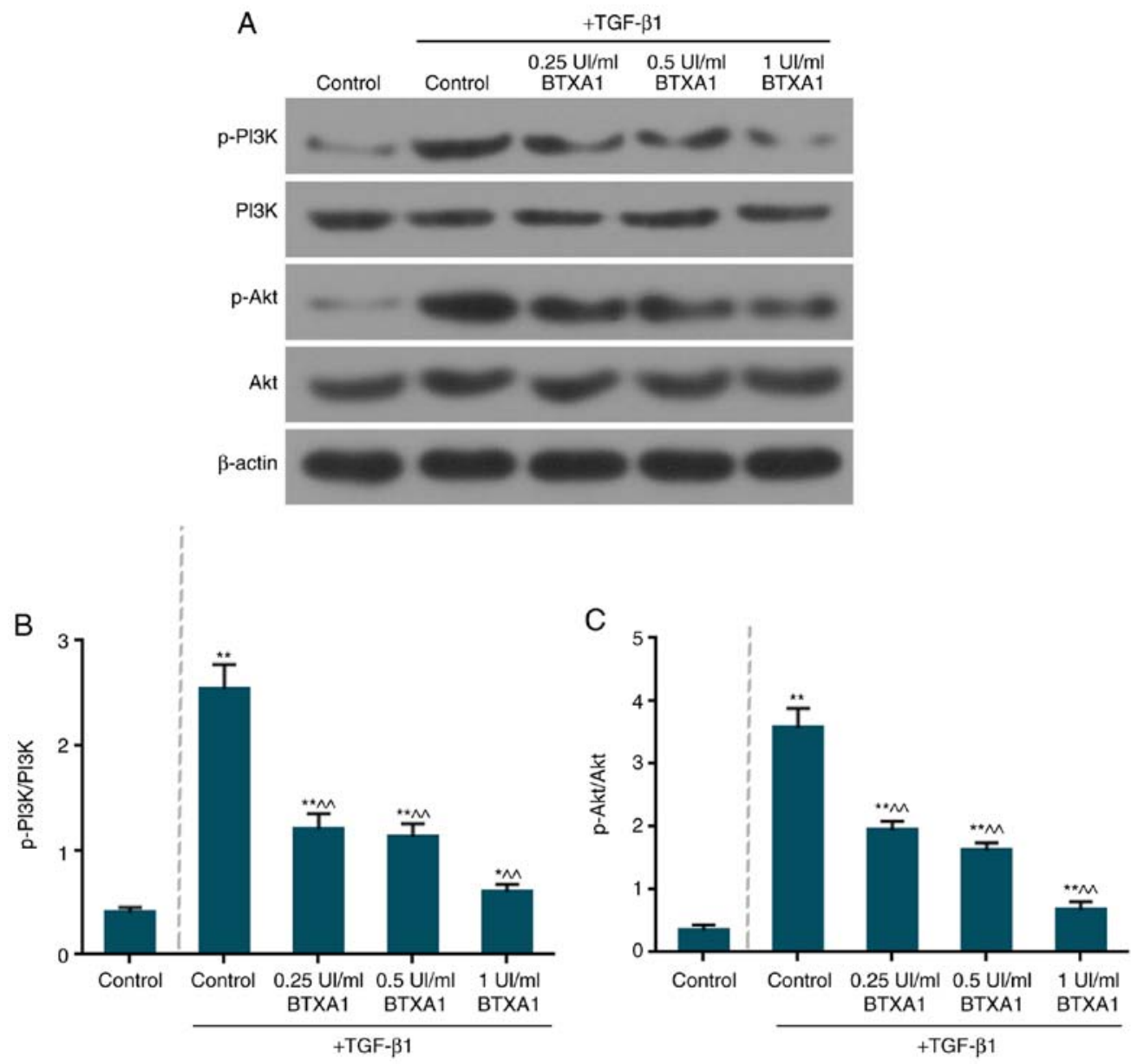

Figure 7. BTXA inactivates the phosphorylation of PI3K and Akt. (A) The protein expression of p-PI3K, PI3K, p-Akt and Akt was examined by western blot analysis. (B) BTXA notably suppressed the ratio of p-PI3K/PI3K. (C) BTXA notably suppressed the ratio of p-Akt/Akt. $\beta$-actin was used as an internal control. Dotted line separation represents whether or not fibroblasts were treated with TGF- $\beta 1$. Data are shown as the means $\pm \mathrm{SD}, \mathrm{n}=3 .{ }^{*} \mathrm{P}<0.05$ and ${ }^{* *} \mathrm{P}<0.01 \mathrm{vs}$. control without TGF- $\beta 1 ;{ }^{\wedge} \mathrm{P}<0.01$ vs. control with TGF- $\beta 1$. 
TGF- $\beta 1$. BTXA reversed this expression pattern. These results suggest that BTXA promotes fibroblast apoptosis.

Abnormal promoter methylation often accounts for the transcriptional inactivation of various molecules associated with apoptosis and tumor suppression (54). DNMTs can catalyze the methylation of $\mathrm{CpG}$ dinucleotides, which are involved in DNA methylation. It has been demonstrated that the decreased expression of PTEN is accompanied by an enhanced level of DNMT1, which is associated with PTEN promoter hypermethylation (55). Moreover, DNMT3a and DNMT3b can methylate non-methylated DNA as de novo methyltransferases (56). In this study, the high DNMT activity induced by TGF- $\beta 1$ was significantly reduced by BTXA. Additionally, the levels of DNMT1, DNMT3a and DNMT3b were also inhibited by BTXA, suggesting that BTXA may prevent PTEN methylation.

The PI3K/AKT pathway has been reported to be negatively regulated by PTEN (57). The reduced expression of PTEN has been reported to activate the PTEN/AKT pathway and to be associated with the pathogenesis of HS (37). The activation of the PI3K/AKT pathway has been demonstrated to promote cell viability and inhibit apoptosis (58). The abnormal PI3K/AKT pathway activation may result in multiple diseases, including HS (59). Moreover, the activated PI3K/AKT pathway can enhance the accumulation of dermal fibroblasts (60). In this study, we found that the expression levels of p-PI3K and p-Akt were significantly increased by TGF- $\beta 1$. However, BTXA can inhibit the phosphorylation of the PI3K and Akt, and this expression pattern is opposite to PTEN expression, indirectly suggesting that the loss of PTEN can activate the PI3K/AKT pathway (61).

In this study, there were still some limitations; for example, the lack of fibroblasts derived from HS in animal models or derived from skin, the absence of one more cell line and the lack of verification experiments with the application of the corresponding PTEN/PI3K/Akt pathway inhibitor. Therefore, further studies on the effects of BTXA on scars of other nature, as well as studies using animal models treated with BTXA, and one more cell line or skin-derived cell line with validation experiments including a signaling inhibitor are required in order to validate our findings.

In conclusion, the findings of this study demonstrated that BTXA inhibited the viability and promoted the apoptosis of fibroblasts induced by TGF- $\beta 1$. The enhanced expression levels of molecules associated with ECM and EMT, which were induced by TGF- $\beta 1$, were suppressed by BTXA. Furthermore, PTEN methylation triggered by TGF- $\beta 1$ was prevented by BTXA and the activities of DNMTs were also suppressed. Moreover, BTXA blocked the phosphorylation of PI3K and Akt. The findings of this study provide a molecular basis for the role of BTXA in the fibroblast phenotypic transformation and a theoretical basis for HS treatment.

\section{Acknowledgements}

Not applicable.

\section{Funding}

No funding was received.

\section{Availability of data and materials}

All data generated or analyzed during this study are included in this published article or are available from the corresponding author on reasonable request.

\section{Authors' contributions}

$\mathrm{XZ}$ and DL made substantial contributions to the conception and design of the study. SN and SY were involved in data acquisition, data analysis and interpretation. HJ and SY performed the experiments, drafted the article or critically revised it for important intellectual content. All authors have read and approved the final manuscript and agree to be accountable for all aspects of the work in ensuring that questions related to the accuracy or integrity of the work are appropriately investigated and resolved.

\section{Ethics approval and consent to participate}

Not applicable.

\section{Patient consent for publication}

Not applicable.

\section{Competing interests}

The authors declare that they have no competing interests.

\section{References}

1. Xiao Z, Zhang F, Lin W, Zhang M and Liu Y: Effect of botulinum toxin type A on transforming growth factor betal in fibroblasts derived from hypertrophic scar: A preliminary report. Aesthetic Plast Surg 34: 424-427, 2010.

2. Butzelaar L, Ulrich MM, Mink van der Molen AB, Niessen FB and Beelen RH: Currently known risk factors for hypertrophic skin scarring: A review. J Plast Reconstr Aesthet Surg 69: 163-169, 2016.

3. Xue $\mathrm{M}$ and Jackson CJ: Extracellular matrix reorganization during wound healing and its impact on abnormal scarring. Adv Wound Care (New Rochelle) 4: 119-136, 2015.

4. Liu J, Wang Y, Pan Q, Su Y, Zhang Z, Han J, Zhu X, Tang C and Hu D: Wnt/ $\beta$-catenin pathway forms a negative feedback loop during TGF- $\beta 1$ induced human normal skin fibroblast-to-myofibroblast transition. J Dermatol Sci 65: 38-49, 2012.

5. Chun Q, ZhiYong W, Fei S and XiQiao W: Dynamic biological changes in fibroblasts during hypertrophic scar formation and regression. Int Wound J 13: 257-262, 2016.

6. Sarrazy V, Billet F, Micallef L, Coulomb B and Desmoulière A: Mechanisms of pathological scarring: Role of myofibroblasts and current developments. Wound Repair Regen 19 (Suppl 1): s10-s15, 2011.

7. Curran TA and Ghahary A: Evidence of a role for fibrocyte and keratinocyte-like cells in the formation of hypertrophic scars. J Burn Care Res 34: 227-231, 2013.

8. Ding J, Ma Z, Shankowsky HA, Medina A and Tredget EE: Deep dermal fibroblast profibrotic characteristics are enhanced by bone marrow-derived mesenchymal stem cells. Wound Repair Regen 21: 448-455, 2013.

9. Gökçinar-Yagci B, Uçkan-Çetinkaya D and Çelebi-Saltik B: Pericytes: Properties, functions and applications in tissue engineering. Stem Cell Rev 11: 549-559, 2015.

10. Yan C, Grimm WA, Garner WL, Qin L, Travis T, Tan N and Han YP: Epithelial to mesenchymal transition in human skin wound healing is induced by tumor necrosis factor-alpha through bone morphogenic protein-2. Am J Pathol 176: 2247-2258, 2010. 
11. Wang X, Chu J, Wen CJ, Fu SB, Qian YL, Wo Y, Wang C and Wang DR: Functional characterization of TRAP1-like protein involved in modulating fibrotic processes mediated by TGF- $\beta /$ Smad signaling in hypertrophic scar fibroblasts. Exp Cell Res 332: 202-211, 2015.

12. Lu L, Saulis AS, Liu WR, Roy NK, Chao JD, Ledbetter S and Mustoe TA: The temporal effects of anti-TGF-beta1, 2, and 3 monoclonal antibody on wound healing and hypertrophic scar formation. J Am Coll Surg 201: 391-397, 2005.

13. Pakyari M, Farrokhi A, Maharlooei MK and Ghahary A: Critical role of transforming growth factor beta in different phases of wound healing. Adv Wound Care (New Rochelle) 2: 215-224, 2013.

14. Yin L, Zhao X, Ji S, He C, Wang G, Tang C, Gu S and Yin C: The use of gene activated matrix to mediate effective SMAD2 gene silencing against hypertrophic scar. Biomaterials 35: 2488-2498, 2014.

15. Zhang YF, Zhou SZ, Cheng XY, Yi B, Shan SZ, Wang J and Li QF: Baicalein attenuates hypertrophic scar formation via inhibition of the transforming growth factor- $\beta / \mathrm{Smad} 2 / 3$ signalling pathway. Br J Dermatol 174: 120-130, 2016.

16. Bai X, He T, Liu J, Wang Y, Fan L, Tao K, Shi J, Tang C, Su L and Hu D: Loureirin B inhibits fibroblast proliferation and extracellular matrix deposition in hypertrophic scar via TGF- $\beta / \mathrm{Smad}$ pathway. Exp Dermatol 24: 355-360, 2015.

17. Zunwen L, Shizhen Z, Dewu L, Yungui M and Pu N: Effect of tetrandrine on the TGF- $\beta$-induced smad signal transduction pathway in human hypertrophic scar fibroblasts in vitro. Burns 38: 404-413, 2012

18. Omranifard M, Heidari M, Farajzadegan Z, Niktabar MR and Motamedi N: Botulinum toxin and burn induces contracture. Arch Plast Surg 43: 609-611, 2016

19. Jeong HS, Lee BH, Sung HM, Park SY, Ahn DK, Jung MS and Suh IS: Effect of botulinum toxin type A on differentiation of fibroblasts derived from scar tissue. Plast Reconstr Surg 136: $171 \mathrm{e}-178 \mathrm{e}, 2015$

20. Gauglitz GG, Bureik D, Dombrowski Y, Pavicic T, Ruzicka T and Schauber J: Botulinum toxin A for the treatment of keloids. Skin Pharmacol Physiol 25: 313-318, 2012.

21. Rasaii S, Sohrabian N, Gianfaldoni S, Hadibarhaghtalab M, Pazyar N, Bakhshaeekia A, Lotti T, Ramirez-Pacheco LA, Lange CS, Matta J, et al: Intralesional triamcinolone alone or in combination with botulinium toxin A is ineffective for the treatment of formed keloid scar: A double blind controlled pilot study. Dermatol Ther 32: e12781, 2019.

22. Xiao Z, Zhang F and Cui Z: Treatment of hypertrophic scars with intralesional botulinum toxin type A injections: A preliminary report. Aesthetic Plast Surg 33: 409-412, 2009

23. Xiao Z and Qu G: Effects of botulinum toxin type a on collagen deposition in hypertrophic scars. Molecules 17: 2169-2177, 2012

24. Lee SD, Yi MH, Kim DW, Lee Y, Choi Y and Oh SH: The effect of botulinum neurotoxin type A on capsule formation around silicone implants: The in vivo and in vitro study. Int Wound J 13: 65-71, 2016.

25. Chen M, Yan T, Ma K, Lai L, Liu C, Liang L and Fu X: Botulinum toxin type $\mathrm{A}$ inhibits $\alpha$-smooth muscle actin and myosin II expression in fibroblasts derived from scar contracture. Ann Plast Surg 77: e46-e49, 2016

26. Xiao Z, Zhang M, Liu Y and Ren L: Botulinum toxin type a inhibits connective tissue growth factor expression in fibroblasts derived from hypertrophic scar. Aesthetic Plast Surg 35: 802-807, 2011.

27. Kim S, Ahn M, Piao Y, Ha Y, Choi DK, Yi MH, Shin N, Kim DW and Oh SH: Effect of botulinum toxin type A on TGF-beta/Smad pathway signaling: Implications for silicone-induced capsule formation. Plast Reconstr Surg 138: 821e-829e, 2016.

28. Li Y, Zhang J, Zhou Q, Wang H, Xie S, Yang X, Ji P, Zhang W, $\mathrm{He} \mathrm{T}$, Liu Y, et al: Linagliptin inhibits high glucose-induced transdifferentiation of hypertrophic scar-derived fibroblasts to myofibroblasts via IGF/Akt/mTOR signalling pathway. Exp Dermatol 28: 19-27, 2019

29. Liu B, Guo Z and Gao W: miR-181b-5p promotes proliferation and inhibits apoptosis of hypertrophic scar fibroblasts through regulating the MEK/ERK/p21 pathway. Exp Ther Med 17: $1537-1544,2019$.

30. Zhang Q, Guo B, Hui Q, Chang P and Tao K: miR-137 inhibits proliferation and metastasis of hypertrophic scar fibroblasts via targeting pleiotrophin. Cell Physiol Biochem 49: 985-995, 2018.

31. Lim CP, Phan TT, Lim IJ and Cao X: Stat 3 contributes to keloid pathogenesis via promoting collagen production, cell proliferation and migration. Oncogene 25: 5416-5425, 2006.
32. Liao WT, Yu HS, Arbiser JL, Hong $\mathrm{CH}$, Govindarajan $\mathrm{B}$ Chai CY, Shan WJ, Lin YF, Chen GS and Lee CH: Enhanced MCP-1 release by keloid CD14+ cells augments fibroblast proliferation: Role of MCP-1 and Akt pathway in keloids. Exp Dermatol 19: e142-e150, 2010.

33. Kulkarni AA, Thatcher TH, Olsen KC, Maggirwar SB, Phipps RP and Sime PJ: PPAR- $\gamma$ ligands repress TGF $\beta$-induced myofibroblast differentiation by targeting the PI3K/Akt pathway: Implications for therapy of fibrosis. PLoS One 6: e15909, 2011.

34. Paterno J, Vial IN, Wong VW, Rustad KC, Sorkin M, Shi Y, Bhatt KA, Thangarajah H, Glotzbach JP and Gurtner GC: Akt-mediated mechanotransduction in murine fibroblasts during hypertrophic scar formation. Wound Repair Regen 19: 49-58, 2011

35. Dey JH, Bianchi F, Voshol J, Bonenfant D, Oakeley EJ and Hynes NE: Targeting fibroblast growth factor receptors blocks PI3K/AKT signaling, induces apoptosis, and impairs mammary tumor outgrowth and metastasis. Cancer Res 70: 4151-4162, 2010

36. Deng B, Yang X, Liu J, He F, Zhu Z and Zhang C: Focal adhesion kinase mediates TGF-beta1-induced renal tubular epithelial-to-mesenchymal transition in vitro. Mol Cell Biochem 340: 21-29, 2010.

37. Guo L, Chen L, Bi S, Chai L, Wang Z, Cao C, Tao L and Li S: PTEN inhibits proliferation and functions of hypertrophic scar fibroblasts. Mol Cell Biochem 361: 161-168, 2012.

38. Takashima M, Parsons CJ, Ikejima K, Watanabe S, White ES and Rippe RA: The tumor suppressor protein PTEN inhibits rat hepatic stellate cell activation. J Gastroenterol 44: 847-855, 2009.

39. White ES, Thannickal VJ, Carskadon SL, Dickie EG, Livant DL, Markwart S, Toews GB and Arenberg DA: Integrin alpha4beta1 regulates migration across basement membranes by lung fibroblasts: A role for phosphatase and tensin homologue deleted on chromosome 10. Am J Respir Crit Care Med 168: 436-442, 2003.

40. Larsson O, Diebold D, Fan D, Peterson M, Nho RS, Bitterman PB and Henke CA: Fibrotic myofibroblasts manifest genome-wide derangements of translational control. PLoS One 3: e3220, 2008

41. Mori T, Okumura M, Matsuura M, Ueno K, Tokura S, Okamoto Y, Minami S and Fujinaga T: Effects of chitin and its derivatives on the proliferation and cytokine production of fibroblasts in vitro. Biomaterials 18: 947-951, 1997.

42. Livak KJ and Schmittgen TD: Analysis of relative gene expression data using real-time quantitative PCR and the 2(-Delta Delta $\mathrm{C}(\mathrm{T}))$ method. Methods 25: 402-408, 2001

43. Jiang B, Zu W, Xu J, Xiong Z, Zhang Y, Gao S, Ge S and Zhang L: Botulinum toxin type A relieves sternocleidomastoid muscle fibrosis in congenital muscular torticollis. Int J Biol Macromol 112: 1014-1020, 2018.

44. Zhao JC, Zhang BR, Hong L, Shi K, Wu WW and Yu JA: Extracorporeal shock wave therapy with low-energy flux density inhibits hypertrophic scar formation in an animal model. Int J Mol Med 41: 1931-1938, 2018.

45. Qiu SS, Dotor J and Hontanilla B: Effect of P144® (Anti-TGF- $\beta$ ) in an 'In Vivo' human hypertrophic scar model in nude mice. PLoS One 10: e0144489, 2015

46. Wang X, Gao Z, Wu X, Zhang W, Zhou G and Liu W: Inhibitory effect of TGF- $\beta$ peptide antagonist on the fibrotic phenotype of human hypertrophic scar fibroblasts. Pharm Biol 54: 1189-1197, 2016.

47. Oliveira GV, Hawkins HK, Chinkes D, Burke A, Tavares AL, Ramos-e-Silva M, Albrecht TB, Kitten GT and Herndon DN: Hypertrophic versus non hypertrophic scars compared by immunohistochemistry and laser confocal microscopy: Type I and III collagens. Int Wound J 6: 445-452, 2009.

48. Wang YW, Liou NH, Cherng JH, Chang SJ, Ma KH, Fu E, Liu JC and Dai NT: siRNA-targeting transforming growth factor- $\beta$ type I receptor reduces wound scarring and extracellular matrix deposition of scar tissue. J Invest Dermatol 134: 2016-2025, 2014

49. Ulrich D, Ulrich F, Unglaub F, Piatkowski A and Pallua N: Matrix metalloproteinases and tissue inhibitors of metalloproteinases in patients with different types of scars and keloids. J Plast Reconstr Aesthet Surg 63: 1015-1021, 2010.

50. Huang D, Liu Y, Huang Y, Xie Y, Shen K, Zhang D and Mou Y: Mechanical compression upregulates MMP9 through SMAD3 but not SMAD2 modulation in hypertrophic scar fibroblasts. Connect Tissue Res 55: 391-396, 2014.

51. Luan Y, Chen M and Zhou L: MiR-17 targets PTEN and facilitates glial scarformation after spinal cord injuries viathe PI3K/Akt/mTOR pathway. Brain Res Bull 128: 68-75, 2017.

52. Pi WF, Guo XJ, Su LP and Xu WG: Troglitazone upregulates PTEN expression and induces the apoptosis of pulmonary artery smooth muscle cells under hypoxic conditions. Int J Mol Med 32: 1101-1109, 2013 
53. Yan YT, Li SD, Li C, Xiong YX, Lu XH, Zhou XF, Yang LQ, $\mathrm{Pu} \mathrm{LJ}$ and Luo HY: Panax notoginsenoside saponins Rb1 regulates the expressions of Akt mTOR/PTEN signals in the hippocampus after focal cerebral ischemia in rats. Behav Brain Res 345: 83-92, 2018.

54. Sanders YY, Pardo A, Selman M, Nuovo GJ, Tollefsbol TO, Siegal GP and Hagood JS: Thy-1 promoter hypermethylation: A novel epigenetic pathogenic mechanism in pulmonary fibrosis. Am J Respir Cell Mol Biol 39: 610-618, 2008.

55. Bian EB, Huang C, Ma TT, Tao H, Zhang H, Cheng C, Lv XW and Li J: DNMT1-mediated PTEN hypermethylation confers hepatic stellate cell activation and liver fibrogenesis in rats Toxicol Appl Pharmacol 264: 13-22, 2012.

56. Wang $X$, Wang Z, Wang Q, Wang H, Liang H and Liu D: Epigenetic modification differences between fetal fibroblast cells and mesenchymal stem cells of the Arbas Cashmere goat. Res Vet Sci 114: 363-369, 2017.

57. Zhu G, Chai J, Ma L, Duan H and Zhang H: Downregulated microRNA-32 expression induced by high glucose inhibits cell cycle progression via PTEN upregulation and Akt inactivation in bone marrow-derived mesenchymal stem cells. Biochem Biophys Res Commun 433: 526-531, 2013.
58. Kitagishi $\mathrm{Y}$ and Matsuda S: Diets involved in PPAR and $\mathrm{PI} 3 \mathrm{~K} / \mathrm{AKT} / \mathrm{PTEN}$ pathway may contribute to neuroprotection in a traumatic brain injury. Alzheimers Res Ther 5: 42, 2013.

59. Zhang Y, Yao X, Jiang C, Yue J, Guan J, Cheng H, Hajirashid M, Wang Y and Fan L: Expression of PI3K, PTEN and Akt in small intestinal adenocarcinoma detected by quantum dots-based immunofluorescence technology. Cancer Biomark 13: 299-305, 2013.

60. Pericacho M, Velasco S, Prieto M, Llano E, López-Novoa JM and Rodríguez-Barbero A: Endoglin haploinsufficiency promotes fibroblast accumulation during wound healing through Akt activation. PLoS One 8: e54687, 2013.

61. Seront E, Pinto A, Bouzin C, Bertrand L, Machiels JP and Feron O: PTEN deficiency is associated with reduced sensitivity to mTOR inhibitor in human bladder cancer through the unhampered feedback loop driving PI3K/Akt activation. Br J Cancer 109: 1586-1592, 2013.

This work is licensed under a Creative Commons Attribution-NonCommercial-NoDerivatives 4.0 International (CC BY-NC-ND 4.0) License. 